\title{
Pengujian Black Box pada Aplikasi Desktop Penjualan Elektronik Menggunakan Metode Equivalence Partitioning
}

\author{
Joko Susanto $^{1}$, Biqirrosyad ${ }^{2}$, Muhamad Mardian Junaidi ${ }^{3}$, Yuliyandri Sudrajat ${ }^{4}$, Teti Desyani ${ }^{5}$ \\ Teknik Informatika, Universitas Pamulang, Tangerang Selatan, Indonesia \\ E-mail: 1anthomars.am@gmail.com, ${ }^{2}$ biqirosyad1511@gmail.com, ${ }^{3}$ muhamadmardian98@ gmail.com, \\ ${ }^{4}$ sudyuliyanddri@gmail.com, ${ }^{5}$ dosen00839@unpam.ac.id
}

Submitted Date: December $23^{\text {rd }}, 2020$

Revised Date: April 01 ${ }^{\text {st }}, 2021$

\author{
Reviewed Date: January $13^{\text {th }}, 2021$ \\ Accepted Date: April 01 ${ }^{\text {st }}, 2021$
}

\begin{abstract}
Software testing requires validation to determine whether it meets the goals and specifications or not. If the validation process is not good, it can result in data being stored that is not good too, for example the login process becomes an error. Of course this will hamper using the application. So that the quality of validation must be improved until it is accurate. The testing phase must be carried out on applications that are designed in such a way that quality software is obtained. In this study we used Blackbox testing with the Equivalence Partitioning method. Namely by dividing or solving the program in the form of an input domain to the data class so that test cases can be obtained. We think this method is quite relevant for testing electronic sales applications. This research includes determining application functionality, designing test scenarios, determining the data to be tested, determining input which can be numerical values, value ranges, Boolean conditions according to the database structure that has been created, testing experiments, documentation of research results and drawing conclusions. The conclusion of this test is that this software is running well. But we realize that this test is not perfect due to the limited sample form. We hope that this application can be used according to user needs.
\end{abstract}

Keywords: Testing; Black Box; Equivalence partitioning

\begin{abstract}
Abstrak
Pengujian software membutuhkan suatu pengabsahan untuk menentukan apakah sudah memenuhi tujuan dan spesifikasi atau belum. Jika proses validasi tidak baik maka bisa mengakibatkan data yang disimpan tidak baik pula, misalnya proses login menjadi eror. Tentunya ini akan menghambat dalam menggunakan aplikasi. Sehingga kualitas validasi harus diperbaiki hingga akurat. Tahap pengujian harus dilakukan pada aplikasi yang dirancang sedemikian rupa hingga didapatkan perangkat lunak yang berkualitas. Dalam penelitian ini kami menggunakan pengujian Blackbox dengan metode Equivalence Partitioning. Yaitu dengan membagi atau memecahkan program berupa domain masukan ke data class agar test case bisa didapat. Metode ini kami nilai cukup relevan untuk menguji aplikasi penjualan elektonik. Penelitian ini meliputi penentuan fungsionalitas aplikasi, perancangan skenario pengujian, penentuan data yang hendak diuji, penentuan masukan yang bisa berupa nilai numerik, kisaran nilai, kondisi Boolean sesuai dengan struktur basis data yang sudah dibuat, percobaan pengujian, dokumentasi hasil penelitian hingga penarikan kesimpulan. Kesimpulan dari pengujian ini yaitu bahwa perangkat lunak ini berjalan dengan baik. Tetapi kami menyadari bahawa pengujian ini belum sempurna dikarenakan form sampel yang terbatas. Kami berharap semoga aplikasi ini bisa dipakai menurut kebutuhan user.
\end{abstract}

\section{Kata Kunci: Pengujian; Black Box; Equivalence partitioning}

\section{Pendahuluan}

Pengujian software yaitu tentang bagaimana memastikan perangkat lunak yang dibuat berjalan sesuai fungsionalitas yang diharapkan (Hidayat, 2018). Pengujian semacam ini diperlukan sebelum aplikasi diluncurkan.

Pengujian software dilakukan dengan tujuan mencari kelemahannya (Wibisono \& Baskoro, 2016). Sehingga kita bisa memperbaiki 
kesalahan tersebut hingga tercipta perangkat lunak yang diharapkan dan sesuai kebutuhan.

Pengujian sangat diperlukan untuk mengetahui sejauh mana kualiatas suatu software sebelum aplikasi tersebut digunakan secara masal oleh pengguna yang berkepentingan. Sehingga dengan adanya pengujian tersebut pengguna percaya dan tidak ragu bahwa aplikasi bisa berjalan fungsionaliotasnya dengan baik sebagaimana mestinya. Kualitas suatu software adalah hal mutlak yang harus diperhatikan. (Maulana, Liwanto \& Lucman, 2018).

Pengujian ini dirancang dengan tujuan menemukan kesalahan secara sistematis dan bisa memperbaikinya seefisien mungkin. Pengujian yang kami pilih yakni uji Black box memakai metode Equivalence Partitioning. Yaitu meliputi penentuan test case, penentuan kriteria, pendefinisian partisi, pembuatan data uji, pembuatan kasus uji, serta terakhir pengujian dan evaluasi (Pramudita, 2020).

Rencana pengujian ini kami fokuskan pada form login dan form transaksi dengan teknik Equivalence Partitioning. Pengujian dengan teknik Equivalence Partitioning diharapkan mampu membantu test case, serta menemukan kesalahan undetectable akibat kesalahan dalam pengetikan (Pramudita, 2020).

\section{Metodologi}

Tujuan pegujian suatu software adalah untuk mendapatkan sotware yang dibutuhakan. Sehingga nantinya akan didapatkan aplikasi yang diharapkan. Salah satu pengujian yang sangat penting untuk meningkatkan kepercayaan dan kualitas dari perangkat lunak adalah pengujian Black Box. Dimana pengujian ini difokuskan pada spesifikasi fungsional suatu software (Hidayat, 2018). Berbagai kesalahan yang dapat ditemukan melalui pengujian Black Box diantarnya:

1. Fungsi sistem yang salah

2. Masalah kinerja
3. Masalah kegunaan

4. Kesalahan Timing

5. Kesalahan sistem login

6. Dan lain-lain

Secara umum pengujian Equivalence Partitioning dilakukan dengan membuat rancangan test case sesuai fungsi suatu software. Selanjutnya yaitu membuat batasan pengujian, jenis pengujian serta hasil yang diinginkan, dan pengujian berdasarkan jenis yang direncanakan. Semua itu dikerjakan demi memperoleh data berbentuk dokumentasi pengujian metode Equivalence Partitioning serta tinggi-rendahnya keefektifan Equivalence Partitioning Method (Jaya, Gumilang, Wati, Andersen, \& Desyani, 2019).

Pengujian Black box memakai metode Equivalence Partitioning. Yaitu meliputi penentuan test case, penentuan kriteria, pendefinisian partisi, pembuatan data uji, pembuatan kasus uji, serta terakhir pengujian dan evaluasi (Pramudita, 2020). Pengujian ini dirancang dengan tujuan menemukan kesalahan secara sistematis dan bisa memperbaikinya seefisien mungkin.

Pengujian Black Box Equivalence Partitioning yang kami implementasikan pada aplikasi pembayaran elektronik berbasis Jawa Netbeans ini meliputi:

1. Pengujian fungsionalitas form login

2. Pengujian fungsionalitas form transaksi

3. Pengujian fungsionalitas form biodata pembeli untuk mengakhiri proses trasaksi

Sebagaimana yang telah dijelaskan sebelumnya, pengujian ini mempunyai tujuan dalam penentuan keadaan valid/tidak valid terhadap kondisi inputan suatu software atau dengan kata lain untuk memeriksa fungsionalitas perangkat lunak tersebut. Sehingga diharapkan mampu membantu test case, serta menemukan kesalahan yang tidak diketahui akibat kesalahan dalam pengetikan (Pramudita, 2020). 


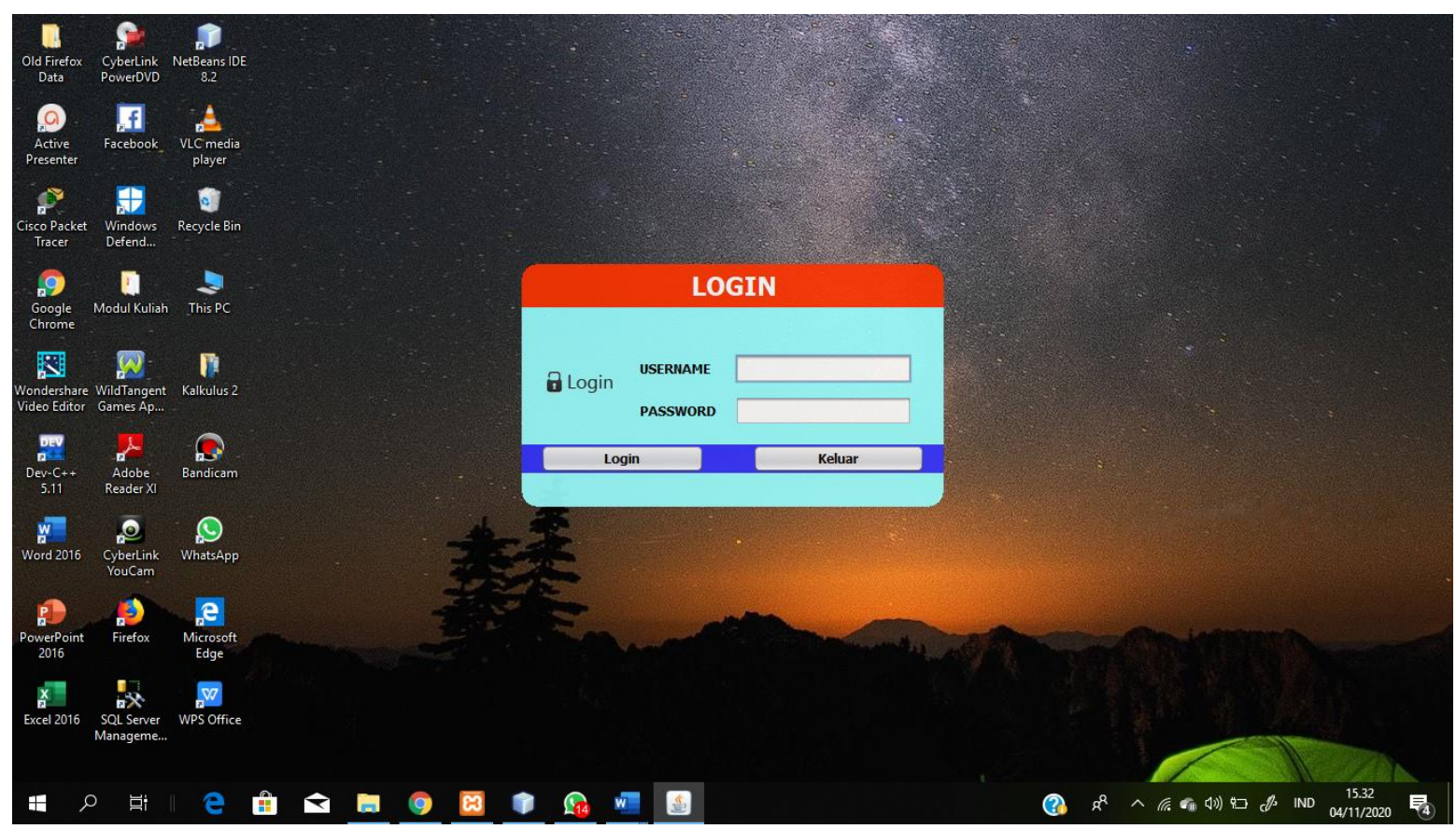

Gambar 1. Form Login

Perhatikan gambar 1 diatas. Data form login akan valid jika username diisi dengan kata "anto0108" dan password diisi dengan "1234". Jika form sudah diisi dengan username dan password tersebut, selanjutnya tekan tombol LOGIN maka Sistem menerima dan menuju ke halaman beranda aplikasi, apabila password salah (contohnya "1290"), otomatis sistem akan menolak serta menampilkan pop up message ("Access Di Tolak, Periksa User ID dan Password Anda!") dan demikian juga bila mengosongkan password maupun username juga akan menampilkan pop up message ("Access Di Tolak, Periksa User ID dan Password Anda!”).

Tabel 1. Konsep Test Case Dari Form Login

\begin{tabular}{|c|l|l|}
\hline Id & \multicolumn{1}{|c|}{ Uraian Test Case } & \multicolumn{1}{|c|}{ Hasil Yang Diinginkan } \\
\hline A01 & $\begin{array}{l}\text { Username diisi } \\
\text { "anto0108, Password diisi "1234" kemudian } \\
\text { tekan tombol "Login" }\end{array}$ & $\begin{array}{l}\text { Sistem menerima, kemudian mengarahkan } \\
\text { ke halaman beranda }\end{array}$ \\
\hline A02 & $\begin{array}{l}\text { Username diisi dengan } \\
\text { "anto0108, Password diisi ndengan } \\
\text { "1290" kemudian tekan tombol "Login" }\end{array}$ & $\begin{array}{l}\text { Sistem akan menolak kemudian } \\
\text { menampilkan pemberitahuan "Access Di Di } \\
\text { Tolak, Periksa User ID dan Password Anda!" }\end{array}$ \\
\hline A03 & $\begin{array}{l}\text { Username dan Password dikosongkan dan } \\
\text { tekan tombol "Login" }\end{array}$ & $\begin{array}{l}\text { Sistem akan menolak dan menampilkan } \\
\text { "Access Di Tolak, Periksa User ID dan } \\
\text { Password Anda!" }\end{array}$ \\
\hline
\end{tabular}




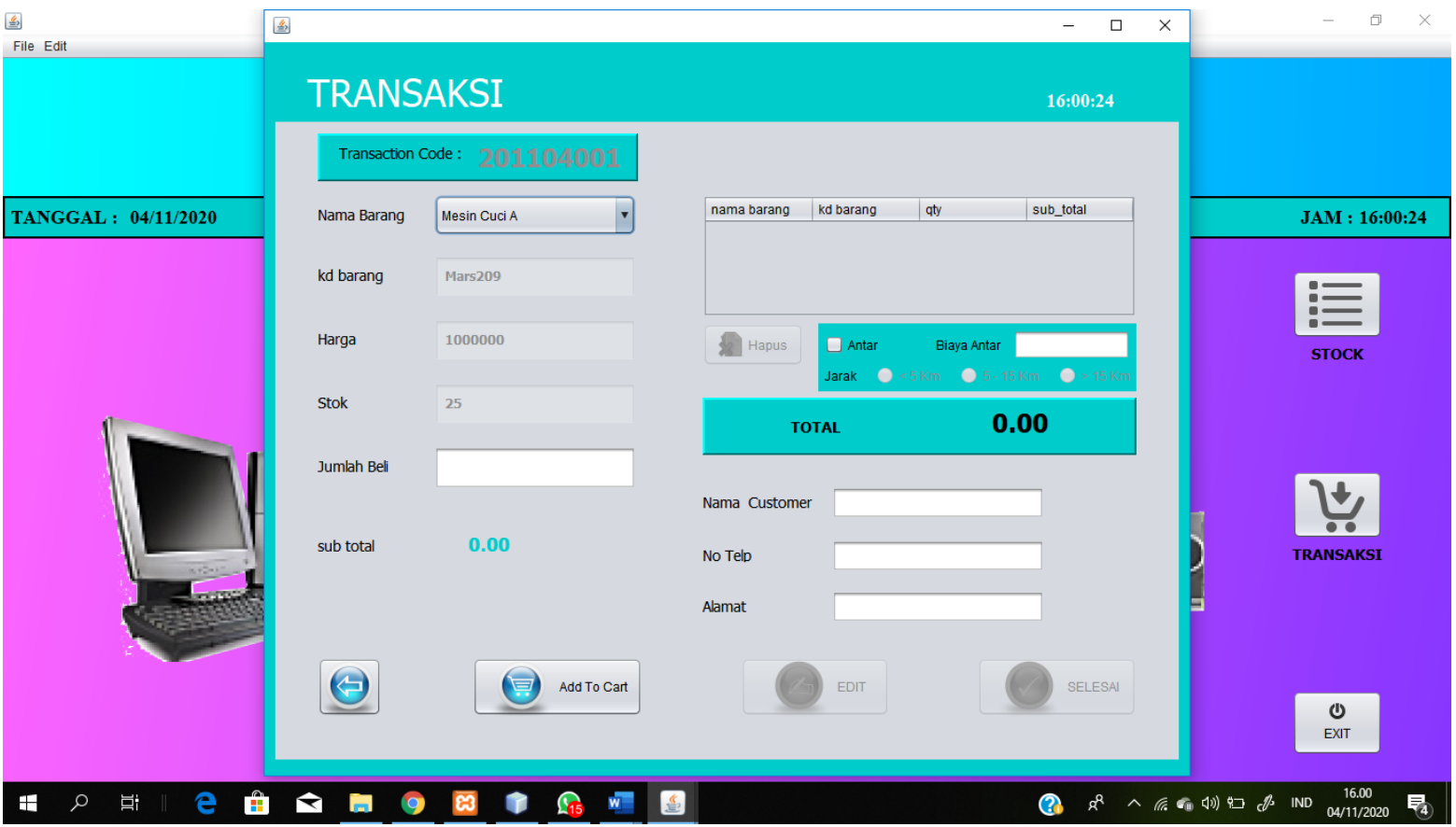

Gambar 2. Form Transaksi

Rencana pengujian selanjutnya yaitu pengujian form transaksi barang. Form harus di isi jumlah pembelian barang, misalnya 2, selanjutnya tekan tombol "Add To Cart" maka sistem akan menerima dan menampilkan pemberitahuan (Pop-Up Message) "Berhasil" dan kemudian barang ke keranjang belanjaan (Cart). Hal ini karena jumlah pembelian barang tidak melebihi jumlah stok. Dan jika kita mengisi jumlah pembelian barang melebihi jumlah stok barang maka maka sistem akan menolak memasukkan ke keranjang belanja.

Tabel 2. Konsep Test Case Dari Form Transaksi Barang

\begin{tabular}{|c|l|l|}
\hline Id & \multicolumn{1}{|c|}{ Uraian Test Case } & \multicolumn{1}{c|}{ Hasil Yang Diinginkan } \\
\hline B01 & $\begin{array}{l}\text { Isi jumlah beli “2” lalu menekan } \\
\text { tombol “Add To Cart" }\end{array}$ & $\begin{array}{l}\text { Sistem menerima dan menampilkan Pop Up Message } \\
\text { "Berhasil!” Kemudian barang masuk ke Cart } \\
\text { (Keranjang) }\end{array}$ \\
\hline B02 & $\begin{array}{l}\text { Mengisi jumlah beli melebihi } \\
\text { melebihi jumlah stok barang }\end{array}$ & Sistem akan menolak \\
\hline
\end{tabular}

Setelah memasukkan semua data belanjaan, selanjutnya mengisi data pembeli yang juga terdapat pada form transaksi ( Gambar 2 ). Jika data pembeli belum di isi dengan lengkap maka tombol SELESAI masih freezed (belum bisa di klik ). Adapun data pembeli yaitu : Nama, No. Telepon dan Alamat. Misalnya saja, kolom
Nama kita isi dengan ("Joko Susanto"), kolom No.Telepon diisi dengan ("0877 1000 2000"), dan kolom Alamat diisi dengan ("Sevila Blok AA/10, BSD"). Setelah mengisi data pembeli dengan lengkap maka tombol SELESAI aktif dan bisa diklik yang kemudian akan tersimpan ke database.

Tabel 3. Konsep Test Case Dari Form Data Customer

\begin{tabular}{|l|l|l|}
\hline Id & \multicolumn{1}{|c|}{ Uraian Test Case } & \multicolumn{1}{|c|}{ Hasil Yang Diinginkan } \\
\hline C01 & $\begin{array}{l}\text { Isi Nama dengan "Joko Susanto", No., Telepon } \\
\text { dengan "0877 1000 2000”, Alamat dengan "Sevila } \\
\text { Blok AA/10, BSD" }\end{array}$ & $\begin{array}{l}\text { Tombol SELESAI terbuka dan setelah di klik } \\
\text { maka belanjaan selesai dan data transaksi } \\
\text { serta biodata pembeli masuk ke database }\end{array}$ \\
\hline C02 & $\begin{array}{l}\text { Tidak mengisi biodata pembeli atau biodata tidak } \\
\text { diisi dengan lengkap }\end{array}$ & Tombol SELESAI terkunci \\
\hline
\end{tabular}




\section{Hasil dan Pembahasan}

Sebelum digunakan oleh pengguna maka perlu dilakukan pengujian pada aplikasi penjualan elektronik ini guna mengetahui kelemahan yang ada pada sistem. Selanjutnya diharapkan kelemahan tersebut bisa diperbaiki.
Berikut ini adalah tabel test case untuk menyimpulkan apakah pengujian Black Box berbasis Equivalence Partitioning terhadap sistem berhasil atau tidak.

Tabel 4. Hasil Uji Equivalence Partitioning

\begin{tabular}{|c|c|c|c|c|}
\hline Id & Uraian Test Case & Hasil Yang Diinginkan & Hasil Uji & Kesimpulan \\
\hline A01 & $\begin{array}{l}\text { Username diisi dengan } \\
\text { "anto0108, Password diisi } \\
\text { dengan } \\
\text { "1234" kemudian tekan tombol } \\
\text { "Login" }\end{array}$ & $\begin{array}{l}\text { Sistem } \\
\text { menerima,kemudian } \\
\text { menuju halaman } \\
\text { beranda }\end{array}$ & $\begin{array}{l}\text { Sistem } \\
\text { menerima,kemudian } \\
\text { menuju halaman } \\
\text { beranda }\end{array}$ & Berhasil \\
\hline A02 & $\begin{array}{l}\text { Username diisi dengan } \\
\text { "anto0108, Password diisi } \\
\text { ndengan } \\
\text { "1290" kemudian tekan tombol } \\
\text { "Login" }\end{array}$ & $\begin{array}{l}\text { Sistem akan menolak } \\
\text { kemudian menampilkan } \\
\text { pemberitahuan "Access } \\
\text { Di Tolak, Periksa User } \\
\text { ID dan Password } \\
\text { Anda!" }\end{array}$ & $\begin{array}{l}\text { Sistem menampilkan } \\
\text { pemberitahuan } \\
\text { "Access Di Tolak, } \\
\text { Periksa User ID dan } \\
\text { Password Anda!" }\end{array}$ & Berhasil \\
\hline A03 & $\begin{array}{l}\text { Username dan Password } \\
\text { dikosongkan dan tekan tombol } \\
\text { "Login" }\end{array}$ & $\begin{array}{l}\text { Sistem menampilkan } \\
\text { "Access Di Tolak, } \\
\text { Periksa User ID dan } \\
\text { Password Anda!" }\end{array}$ & $\begin{array}{l}\text { Sistem menampilkan } \\
\text { pemberitahuan } \\
\text { "Access Di Tolak, } \\
\text { Periksa User ID dan } \\
\text { Password Anda!" }\end{array}$ & Berhasil \\
\hline B01 & $\begin{array}{l}\text { Mengisi jumlah beli "2 (tidak } \\
\text { melebihi stok" lalu menekan } \\
\text { tombol "Add To Cart" }\end{array}$ & $\begin{array}{l}\text { Sistem akan menerima } \\
\text { dan menampilkan ke } \\
\text { Cart }\end{array}$ & $\begin{array}{l}\text { Sistem menerima dan } \\
\text { menampilkan ke Cart }\end{array}$ & Berhasil \\
\hline B02 & $\begin{array}{l}\text { Mengisi jumlah beli melebihi } \\
\text { melebihi jumlah stok barang }\end{array}$ & Sistem akan menolak & Sistem menolak & Berhasil \\
\hline $\mathrm{C} 01$ & $\begin{array}{l}\text { Mengisi Nama dengan "Joko } \\
\text { Susanto", No. Telepon dengan } \\
\text { "0877 } 1000 \text { 2000", dan Alamat } \\
\text { dengan "Sevila Blok AA/10, } \\
\text { BSD" }\end{array}$ & $\begin{array}{l}\text { Tombol SELESAI akan } \\
\text { terbuka dan setelah di } \\
\text { klik maka belanjaan } \\
\text { selesai dan data } \\
\text { transaksi serta biodata } \\
\text { pembeli masuk ke } \\
\text { database }\end{array}$ & $\begin{array}{l}\text { Tombol SELESAI } \\
\text { terbuka dan setelah } \\
\text { di klik maka } \\
\text { belanjaan selesai } \\
\text { dan data transaksi } \\
\text { serta biodata } \\
\text { pembeli masuk ke } \\
\text { database } \\
\end{array}$ & Berhasil \\
\hline $\mathrm{C} 02$ & $\begin{array}{l}\text { Tidak mengisi biodata pembeli } \\
\text { atau biodata tidak diisi dengan } \\
\text { lengkap }\end{array}$ & $\begin{array}{l}\text { Tombol SELESAI akan } \\
\text { terkunci }\end{array}$ & $\begin{array}{l}\text { Tombol SELESAI } \\
\text { terkunci }\end{array}$ & Berhasil \\
\hline
\end{tabular}

\section{Kesimpulan}

Pengujian Black Box dengan metode Equivalence Partioning terhadap aplikasi desktop penjualan dapat disimpulkan dalam pengujian tidak ditemukan kesalahan. Fungsionalitas sistem berjalan sesuai yang diharapkan.

\section{Saran}

Software Penjualan Elektronik Berbasis Java NetBeans ini dapat dikembangkan lagi supaya lebih user friendly dan bisa memberikan informasi data yang lebih akurat serta menampilkan desain antar muka yang lebih menarik. Pengujian white box juga bisa diimplementasikan dalam aplikasi ini untuk 
menguji kesalahan internal perangkat lunak. Sehingga nantinya diharapkan aplikasi ini bisa jauh lebih sempurna dari yang sekarang ini dari segi fungsionalitas sistem maupun dari segi internal sistem. Dengan demikian user akan jauh lebih puas dan nyaman dalam menggunakan aplikasi ini nantinya.

\section{Referensi}

Hidayat, T. (2018). Pengujian Sistem Informasi Pendaftaran dan Pembayaran Wisuda Online Menggunakan Black Box Testing Dengan Metode Equivalence Partitioning dan Boundary Value Analysis. Jurnal Teknik Informatika UNIS, 1-5.

Ikhlas, M. (2018). Perancangan Sistem Informasi Pengolahan Data Tabungan Baitul Maal Wat Tamwil (BMT) Menggunakan Pemrograman Java Dan Database MySQL. Jurnal Pelita Informatika, 302308.
Jaya, M., Gumilang, P., Wati, T., Andersen, Y., \& Desyani, T. (2019). Pengujian Black Box Pada Aplikasi Sistem Penunjang Keputusan Seleksi Calon Pegawai Negeri Sipil Menggunakan Teknik Equivalence Partitions. Jurnal Informatika Universitas Pamulang, 131136.

Maulana, R., Liwanto, I., \& Lucman, C. (2018). Software Testing Pada Aplikasi Website PT Semen Tonasa Menggunakan Metode Assasment Vulnerability. Jurnal Insypro UIN Alauddin, 1-4.

Pramudita, R. (2020). Pengujian Black Box Pada Aplikasi Ecampus Menggunakan Metode Equivalence Partitioning. Journal of Informatics, 193-202.

Wibisono, W., \& Baskoro, F. (2016). Pengujian Perangkat Lunak Dengan Menggunakan Model Behavior UML. Jurnal Ilmiah Teknologi Informasi, 1-8. 